\title{
Three Dimensional mapping of the root apex: distances between apexes and anatomical structures and external cortical plates
}

\section{Carlos Henrique FERRARI ${ }^{(a)}$ \\ Amjad ABU HASNA ${ }^{(a)}$ \\ Frederico Canato MARTINHO(b)}

(a) Universidade Estadual Paulista - Unesp, Institute of Science and Technology, Department of Restorative Dentistry, São José dos Campos, SP, Brazil.

(b) University of Maryland, School of Dentistry, Department of Advanced Oral Sciences and Therapeutics, Baltimore, MD, USA.

Declaration of Interests: The authors certify that they have no commercial or associative interest that represents a conflict of interest in connection with the manuscript.

Corresponding Author:

Amjad Abu Hasna

E-mail: d.d.s.amjad@gmail.com

Submitted: March 17, 2020

Accepted for publication: October 8, 2020

Last revision: October 28, 2020
Abstract: This study aimed to determine the mean distances between apexes of the maxillary posterior teeth and the maxillary sinus, between apexes of the mandibular posterior teeth and the mandibular canal, and between the root apexes of all teeth and the adjacent cortical plates. A total of 800 cone-beam computed tomography (CBCT) scans (400 maxillary and 400 mandibular) were obtained from patients indicated for several treatments. The proximity between apexes and anatomical structures, and the relationship between apexes and adjacent cortical plates were assessed together with the risk of over-instrumentation. Paired-sample comparisons were performed by using the paired $t$-test. The means were compared by ANOVA, Kruskal-Wallis and Dwass-Steel-Critchlow-Fligner tests. a) Most of the apexes classified as A (high-risk proximity) were observed in maxillary first and second molars, in mandibular first and second molars, and in second premolars in relation to near anatomical structures. b) A predominance of class A (86.42\%) was noticed in the first premolars, between apexes of maxillary teeth and adjacent cortical plates. c) The distance between apexes of mandibular teeth and buccal cortical plates showed a predominance of medium-risk proximity (B) in all the groups, except the first premolars, with the highest risk $(82.22 \%)$, and the second molars, with low-risk proximity (C) to distal and mesiobuccal apexes (91.77\% and 89.62\%). CBCT images are important for endodontic diagnosis and treatment, since many teeth have high risk proximity to near anatomical structures and adjacent cortical plates.

Keywords: Cone-Beam Computed Tomography; Maxillary Sinus; Tooth Apex.

\section{Introduction}

Tooth pulp can be injured due to a variety of irritants, and root canal treatment (RCT) may be indicated in some cases to restore teeth wellness. ${ }^{1,2,3}$ However, teeth are positioned near sensitive anatomical structures, such as the maxillary sinus and mandibular canal $1^{4,5,6,7,8,9,10,11,1}$ 2,13,14,15,16,17 and the buccal and lingual cortical plates. . $7,70,14,18,19,20,21,22,23$ Thus, the endodontic diagnosis and treatment planning of such cases require greater attention by the endodontist. 
Chemical, physical and biological injuries affect these sensitive anatomical areas during root canal treatment, ranging from minor severity with spontaneous resolution to more severe accidents requiring surgical intervention, including sodium hypochlorite overflow, endodontic instrument fracture, debris and obturation cement extrusion, and labio-mandibular paresthesia, among others. ${ }^{24,25,26,27,28}$ A technique of particular concern is apical foramen widening, which allows a great amount of chemical and mechanical intrusion in the periapical area during instrumentation, ${ }^{29,30}$ whereas instrumentation should not advance beyond the apical foramen. ${ }^{31}$

For many years, an electronic apex locator was considered an accurate device to locate the root apex. ${ }^{32}$ However, it was proved that this accuracy was affected by the proximity of teeth to certain anatomical structures. ${ }^{33,34}$

Periapical radiographic examination is usually used during the diagnosis and treatment of the root canal; however, it does not provide an adequate estimate of the apical position anatomically. ${ }^{35}$ Cone beam computed tomography (CBCT) is the most suitable resource, since it provides a three-dimensional view of the dental anatomy, and its relationship with adjacent anatomical regions, thus enabling overlapping structures to be viewed and eliminating image distortions. ${ }^{36}$

This inaccuracy in determining the root canal working length, and the distance between the apical foramen and the close anatomical structures may result in injury to these structures. Therefore, the aim of this study was to determine the mean distances between the apexes of the maxillary posterior teeth and the inferior wall of the maxillary sinus, determine the mean distances between the apexes of the mandibular posterior teeth and the superior border of the mandibular canal, and measure the proximity between the root apexes of whole teeth in relation to the adjacent cortical plates.

\section{Methodology}

A total of 800 CBCT scans (400 maxillary and 400 mandibular) were obtained from patients indicated for several treatments. The exclusion criteria were
CBCT scans of patients with fewer than eight teeth per dental arch, younger than 21 years old, and scans with image distortions or technical errors. Teeth presenting apical resorption, root dilaceration, root anomalies, root fracture, periapical bone rarefaction and absence of a crown were also excluded. A total of 13,388 apexes of 9,669 teeth, including 7,876 apexes of 5,104 maxillary teeth, and 5,512 apexes of 4,565 mandibular teeth, were studied after approval by the research ethics committee of the Institute of Science and Technology, São Paulo State University ( $\left.\mathrm{n}^{\circ} 1.079 .312\right)$, and in compliance with the Helsinki Declaration.

The images were obtained using the same volumetric CT machine (GX CB 500, Gendex/Kavo, Bieberach, Germany) operating at a voxel of 0.20 , FOV of $14 \mathrm{~cm} \times 8 \mathrm{~cm}, 120 \mathrm{kVp}, 36.15 \mathrm{mAs}$ and 12 bits of grayscale depth. The image data were recorded in DICOM format and reconstructed with specific imaging software (Image Studio ${ }^{\circledR}$ (AnneSolutions, São Paulo, Brazil), so that sagittal and axial sections could be obtained at a standard distance of $1.0 \mathrm{~mm}$. All the measurements were performed by only one professional (dentist, radiologist and endodontist). R software (R Foundation, Vienna, Austria) was used for data analysis. Paired-sample comparisons were performed by using the paired t-test. The means were compared among three independent groups, according to ANOVA (analysis of variance) with the non-parametric Kruskal-Wallis test, followed by the Dwass-Steel-Critchlow-Fligner test to obtain $p$-values adjusted for multiple comparisons, when needed. All $p$-values were two-sided, and were considered significant or marginally significant (respectively, $\mathrm{p}<0.05$ and $\mathrm{p} \leq 0.05, \mathrm{p} \leq 0.10$ ).

\section{Assessment of the proximity between apexes and anatomical structures}

All maxillary and mandibular premolars and molars, as well as maxillary canines, were selected for evaluation, totaling 5,864 teeth. Sagittal sections with a centralized image of each root apex were selected for linear measurements (in $\mathrm{mm}$ ) between maxillary tooth apexes and the point closest to the inferior wall of the maxillary sinus, and between apexes of mandibular teeth and the point closest to the superior border of the mandibular canal. 
Image projection of the apexes onto the maxillary sinus or the mandibular canal was represented by negative values.

The resulting values were then submitted to descriptive statistical analysis (i.e. mean, standard deviation, minimum and maximum values), analyzing each root separately. The data were submitted to inferential statistical analysis for comparison between right and left sides, between genders and among age groups.

Next, the results were grouped and classified according to the interval of measurements, and were then designated according to the risk of proximity to the anatomical structures, namely: A (high risk), with an apex at a distance of up to $1 \mathrm{~mm}$ from the anatomic structure; B (medium risk) with an apex at a distance of 1 to $3 \mathrm{~mm}$; and C (low risk), with an apex at a distance greater than $3 \mathrm{~mm}$.

\section{Assessment of the relationship between apexes and cortical plates}

Axial reconstructions of apical images were selected to assess the relationship between root apexes and buccal and lingual cortical plates. Measurements of the distance between the apex of each root and the point closest to the adjacent outer cortical plate were performed as follows:

a. In the maxilla, distances between the apexes of the buccal roots of premolars and molars and the apexes of roots of anterior teeth to the buccal cortical plate; and between apexes of the palatal roots of premolars and molars and palatal cortical plate;

b. In the mandible, distances between the apexes of buccal and distal roots of molars and the apexes of roots of premolars and anterior teeth to the buccal cortical plate; and between lingual and distal apexes of molars and the apexes of roots of premolar teeth to the lingual cortical plate. However, the distance between the apex of anterior teeth to the lingual cortical plate was not considered due to the thinner thickness of the alveolar bone in the region.

Next, the intervals of mean measurements between root apexes and cortical plates were also grouped and classified by intervals of measurement, and designated according to the risk of proximity to the adjacent external cortical plate, namely: A (high risk), with an apex at a distance of up to $1 \mathrm{~mm}$ from the anatomic structure; B (medium risk), with an apex at a distance of 1 to $3 \mathrm{~mm}$; and $\mathrm{C}$ (low risk), with an apex at a distance greater than $3 \mathrm{~mm}$.

\section{Results}

\section{Assessment of the proximity between apexes and anatomical structures}

The means of distances between the inferior wall of the maxillary sinus and root apexes of maxillary teeth are presented in Table 1. Figure 1 shows the results of intervals classified as A (high risk), B (medium risk) or $\mathrm{C}$ (low risk), according to the distance between the root apex and the inferior wall of the maxillary sinus per tooth. The majority of the apexes classified as A (i.e. less than $1 \mathrm{~mm}$ from the buccal cortical bone) were observed in the first and second molars.

The means of distances between the mandibular canal or mental foramen and root apexes of mandibular teeth are presented in Table 2. Figure 2 shows the results of intervals classified as $\mathrm{A}, \mathrm{B}$ or $\mathrm{C}$, according to

Table 1. Linear measurements (in $\mathrm{mm}$ ) between the maxillary tooth apexes and the lower wall of the maxillary sinus.

\begin{tabular}{|c|c|c|c|c|c|c|c|c|c|c|}
\hline \multirow{2}{*}{$\begin{array}{l}\text { Tooth } \\
\text { Apex }\end{array}$} & \multicolumn{3}{|c|}{$2^{\text {nd }}$ Molar } & \multicolumn{3}{|c|}{$1^{\text {st }}$ Molar } & \multirow{2}{*}{$2^{\text {nd }}$ Premolar } & \multicolumn{2}{|c|}{$1^{\text {st }}$ Premolar } & \multirow{2}{*}{ Canine } \\
\hline & DB & $\mathrm{P}$ & $M B$ & DB & $\mathrm{P}$ & $M B$ & & $P$ & B & \\
\hline Mean & 0.7 & 1.21 & 0.37 & 1.08 & 0.9 & 1.34 & 2,92 & 5,33 & 6,19 & 4,34 \\
\hline Minimum & -7.38 & -3.33 & -5.92 & -9.93 & -9.66 & -9.44 & $-3,07$ & $-2,79$ & $-2,55$ & $-1,64$ \\
\hline Maximum & 10.47 & 7.6 & 7.66 & 11.92 & 8.93 & 11.92 & 14,28 & 14,55 & 15,36 & 11,02 \\
\hline SD & 1.89 & 1.89 & 1.9 & 2.23 & 2.16 & 2.64 & 3,59 & 3,66 & 3,91 & 2,35 \\
\hline $\mathrm{n}$ & & 763 & & & 623 & & 728 & & & 843 \\
\hline
\end{tabular}

SD: standard deviation, DB: distobuccal root, P: palatal root, MB: mesiobuccal root, B: buccal root. 


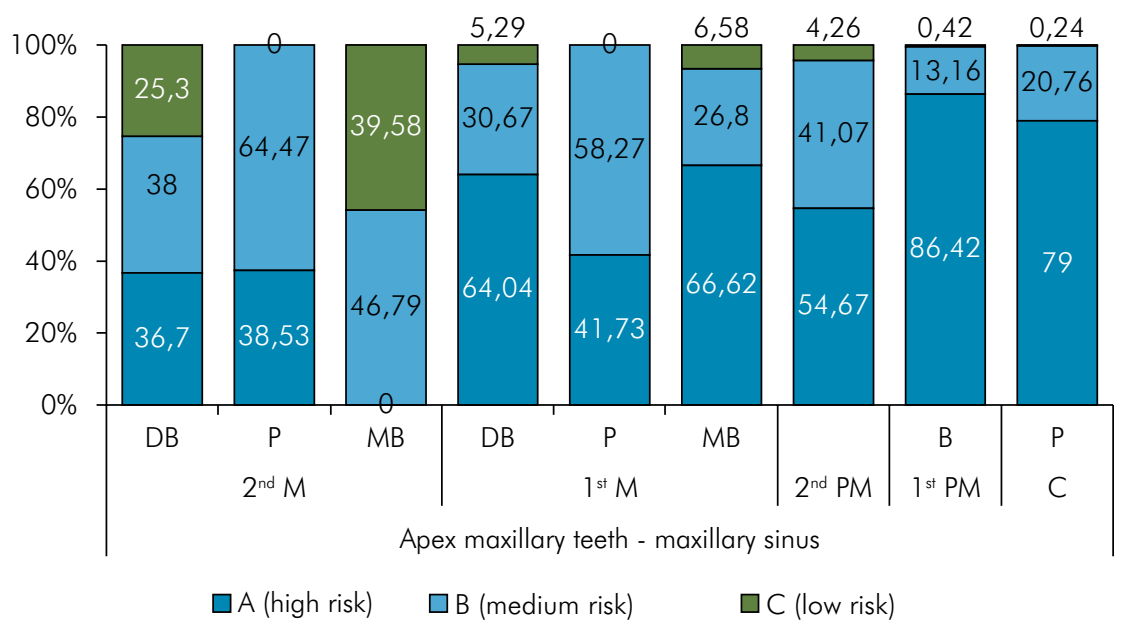

Figure 1. Percentage of classification of intervals according to the distance between root apexes and maxillary sinus. (DB $=$ distobuccal root, $\mathrm{P}=$ palatal root, $\mathrm{MB}=$ mesiobuccal root, $\mathrm{B}=$ buccal root, $\mathrm{P}=$ palatal root, $\mathrm{C}=$ canine).

the distance between the root apex and the mandibular canal. The percentage of high-risk proximity (A) was found to be smaller in relation to the maxilla, with a greater number of higher percentages occurring in the apexes of second molars (mesiobuccal root $=12.88 \%$, mesiolingual root $=10.73 \%$ and distal root $=19.85 \%$ ) and second premolars (13.1\%).

Statistical tests showed no difference in the distances measured between apexes and maxillary sinus or mandibular canal, when comparing left and right sides, genders or age groups $(\mathrm{p}>0.05)$.

\section{Assessment of the relationship between apexes and cortical plates}

A predominance of high-risk proximity (A) of up to $86.42 \%$ in the first premolars was found, based on a classification of risk proximity between apexes of maxillary teeth and adjacent cortical plates. The exception occurs in the apexes of second molars, since there is uniform distribution among the groups (Figure 3).
Regarding the classification of the distance between apexes of mandibular teeth and buccal cortical plates, the results showed a predominance of medium-risk proximity (B) in all the groups, with the highest risk being observed in the first premolars $(82.22 \%)$, and low-risk proximity (C) to distal and mesiobuccal apexes in the second molars, respectively, $91.77 \%$ and $89.62 \%$ (Figure 4 ).

On the other hand, the predominance was of low-risk proximity to the lingual cortical plate (C). Again, the second molars had the highest percentage of high-risk proximity to distal and mesiobuccal apexes, respectively, 54.03\% and 51.89\% (Figure 5).

\section{Discussion}

CBCT was the most precise and reliable method to use in conducting this study. It has the potential to become the first choice for endodontic treatment planning and outcome assessment. ${ }^{36}$ Prior to the

Table 2. Linear measurements (in $\mathrm{mm}$ ) between the mandibular tooth apexes and the upper border of the mandibular canal.

\begin{tabular}{|c|c|c|c|c|c|c|c|c|}
\hline \multirow{2}{*}{$\begin{array}{l}\text { Tooth } \\
\text { Apex }\end{array}$} & \multicolumn{3}{|c|}{$2^{\text {nd }}$ Molar } & \multicolumn{3}{|c|}{$1^{\text {st }}$ Molar } & \multirow{2}{*}{$2^{\text {nd }}$ Premolar } & \multirow{2}{*}{$1^{\text {st }}$ Premola } \\
\hline & D & ML & $M B$ & $\mathrm{D}$ & $M L$ & $M B$ & & \\
\hline Mean & 2.81 & 3.67 & 3.54 & 4.00 & 4.92 & 4.81 & 3.59 & 4.46 \\
\hline Minimum & -3.19 & -1.95 & -1.95 & -1.33 & 0 & 0 & -1.71 & -1.1 \\
\hline Maximum & 11.58 & 13.47 & 13.16 & 9.51 & 12.79 & 12.28 & 11.8 & 12 \\
\hline SD & 2.27 & 2.62 & 2.55 & 2.23 & 2.58 & 2.43 & 2.29 & 2.35 \\
\hline $\mathrm{n}$ & & 559 & & & 388 & & 626 & 620 \\
\hline
\end{tabular}

SD: standard deviation, DB: distobuccal root, P: palatal root, MB: mesiobuccal root, B: buccal root. 


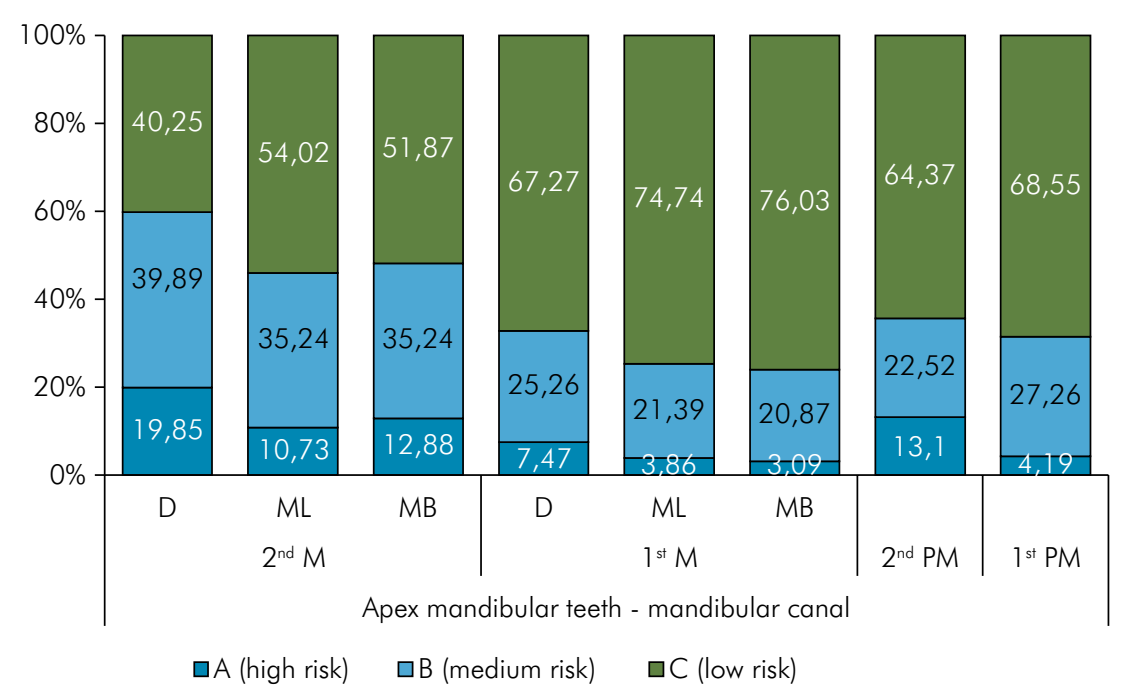

Figure 2. Percentage of classification of intervals according to the distance between root apexes and mandibular canal. $(\mathrm{DB}=$ distobuccal root, $\mathrm{P}=$ palatal root, $\mathrm{MB}=$ mesiobuccal root, $\mathrm{B}=$ buccal root, $\mathrm{P}=$ palatal root, $\mathrm{C}=$ canine).

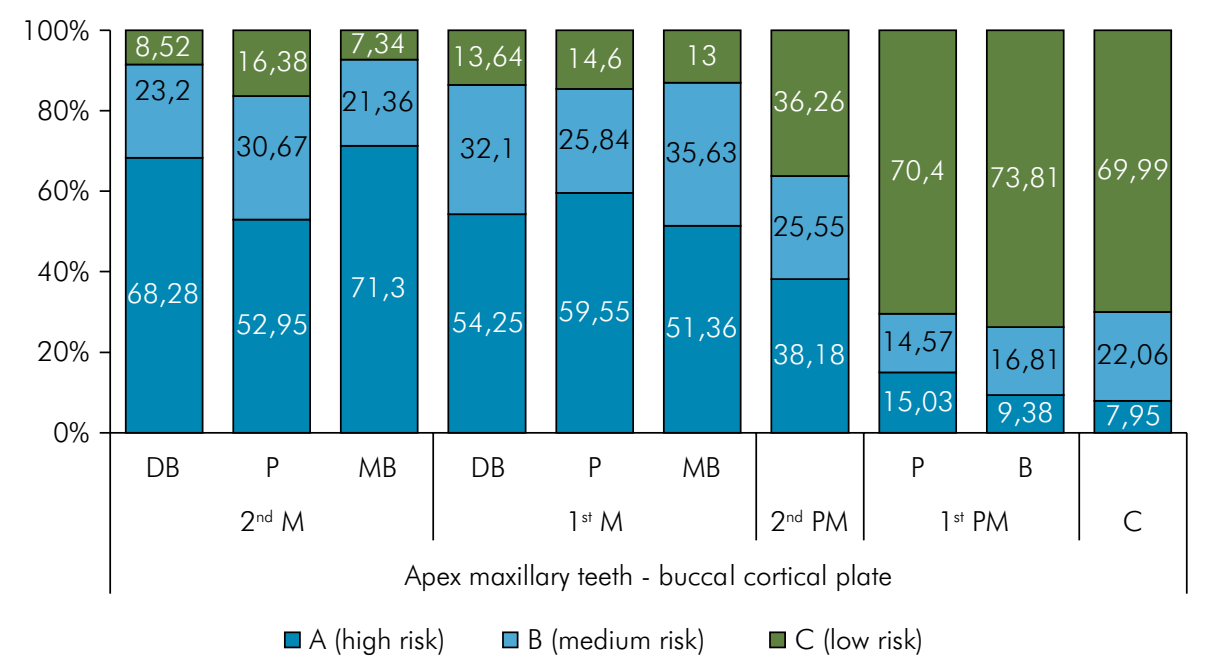

Figure 3. Percentage of classification of intervals according to the distance between maxillary root apexes and buccal cortical plates. ( $\mathrm{DB}=$ distobuccal root, $\mathrm{P}=$ palatal root, $\mathrm{MB}=$ mesiobuccal root, $\mathrm{B}=$ buccal root, $\mathrm{P}=$ palatal root, $\mathrm{C}=$ canine).

advent of CBCT, the apical region could not be accessed with the three-dimensional visualization needed for endodontic treatment planning. ${ }^{35} \mathrm{CBCT}$ application has stepped up in recent years, bringing real benefits to clinical practice through several studies that have investigated the use of CBCT in endodontics, and have justified its application in all phases of endodontic treatment, mainly in situations in which there are doubts or difficulties in routine radiographic diagnoses. ${ }^{35,36,37,38}$
Some patients and professionals are concerned about using CBCT for endodontic diagnosis and treatment, since its radiation dose is higher than that emitted by panoramic radiographic equipment. ${ }^{38}$ However, its estimated effective doses are significantly lower if dose reduction protocols are put into place. Therefore, information about the radiation dose should be shared with patients and not withheld, rather than making this a reason for avoiding CBCT examination. ${ }^{39}$ 


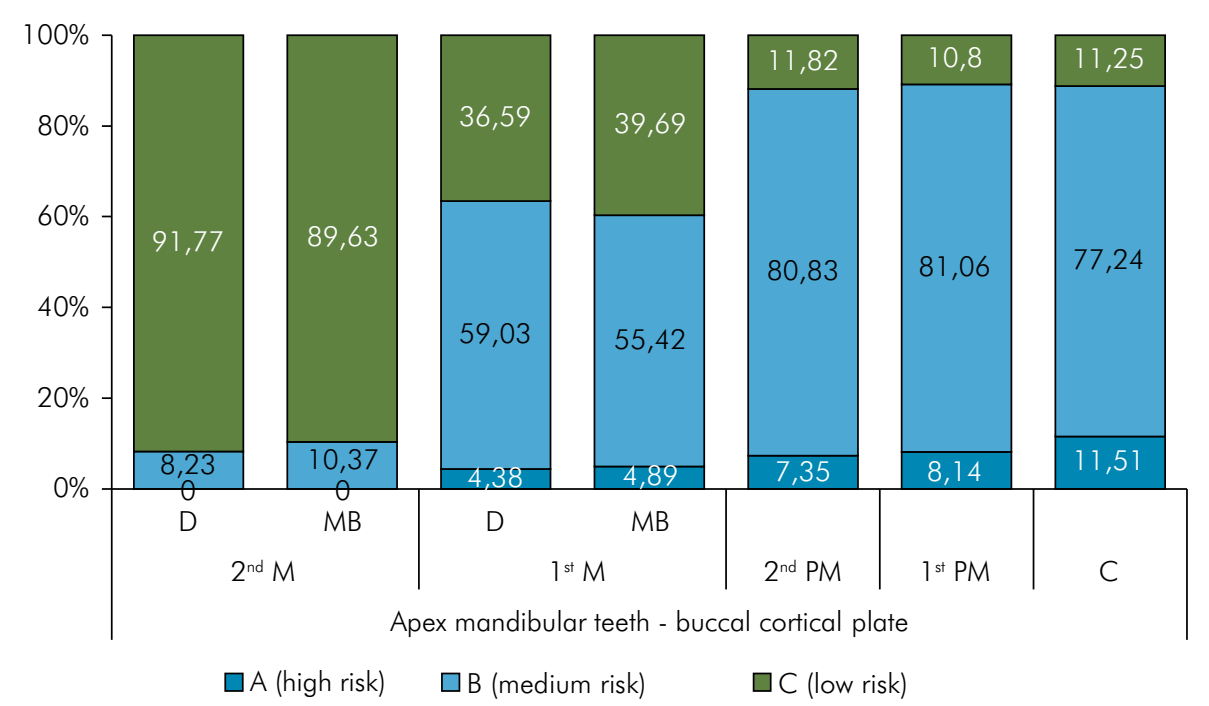

Figure 4. Percentage of classification of intervals according to the distance between mandibular root apexes and buccal cortical plates. ( $\mathrm{DB}=$ distobuccal root, $\mathrm{P}=$ palatal root, $\mathrm{MB}=$ mesiobuccal root, $\mathrm{B}=$ buccal root, $\mathrm{P}=$ palatal root, $\mathrm{C}=$ canine).

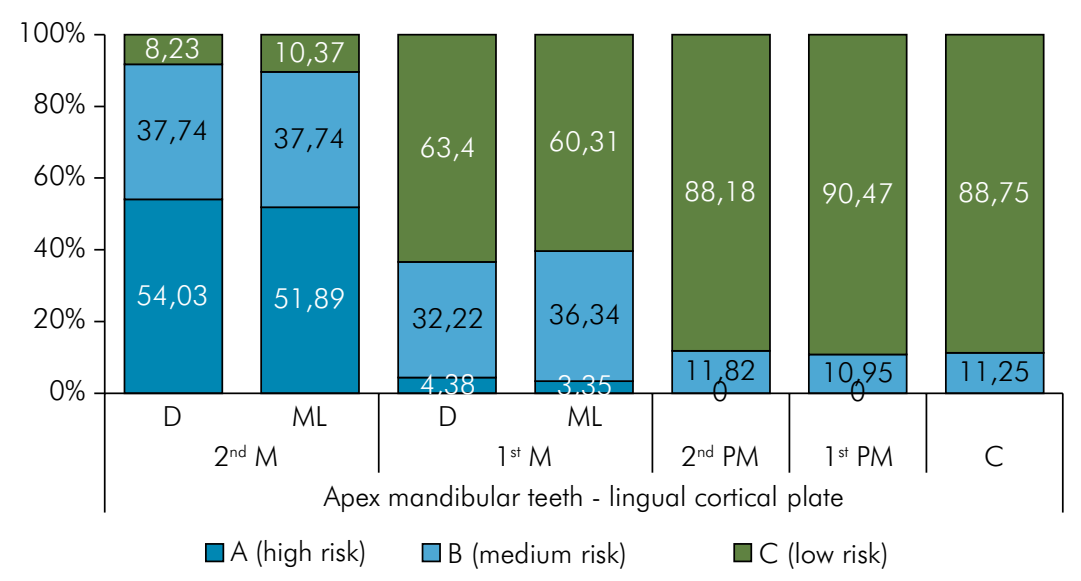

Figure 5. Percentage of classification of intervals according to the distance between mandibular root apexes and lingual cortical plates. ( $\mathrm{DB}=$ distobuccal root, $\mathrm{P}=$ palatal root, $\mathrm{MB}=$ mesiobuccal root, $\mathrm{B}=$ buccal root, $\mathrm{P}=$ palatal root, $\mathrm{C}=$ canine).

\section{Assessment of the proximity between apexes and anatomical structures}

Different studies in the literature have sought to assess the distances of the teeth from only one arch to the nearest anatomical structure, using small samples and CBCT as the evaluation method. These include several in vivo studies that have measured the distances between dental apexes and the maxillary sinus or the mandibular canal, 5,7,9,11,15,17 or dried skull or cadaver studies, ${ }^{4,10,14}$ or else the technique of associating panoramic radiographs.39 Only one study used a larger sample size, involving $627 \mathrm{CBCTs} .^{8}$ This study assessed all posterior teeth of the maxilla and mandible, except third molars, and produced a sample larger than that of most studies in the literature.

The mean distances found between apexes of posterior maxillary teeth and the maxillary sinus show that molars are closely related to this anatomical structure, thus requiring caution in determining the working length and in instrumentation during endodontic treatment. A large percentage of molar apexes were less than $1 \mathrm{~mm}$ from the lower wall of the maxillary sinus. The percentage of second molars at the same distance was somewhat lower, that is, $40 \%$.

The results found in the present study corroborate those in the literature, mostly studies using CBCT 
measurements. ${ }^{6,712,17}$ The greatest discrepancies were found mainly in molars and in studies performing direct measurements in dried skulls and cadavers.,14

The mean distances found between mandibular teeth and the mandibular canal were greater than those measured between maxillary molars and the maxillary sinus. However, there were negative minimum distances in all the groups studied, and the percentages of distances less than $1 \mathrm{~mm}$ between apex and mandibular canal were two digits in all apexes of the second molars. The present study presented results similar to those reported in the literature. ${ }^{5,8,9,13,16,17}$ In contrast, discrepant results were reported by one study on dried skulls with higher means, ${ }^{10}$ and another study using CBCT images with lower means. ${ }^{13}$

Unlike other studies in the literature, ${ }^{5,9,13,16,17}$ this study evaluated the measurements between apexes of mandibular first premolars and mental foramen, or the anterior extension of the mandibular canal or anterior canal loop. The importance of this distance between tooth apexes and these structures is related to the significant percentage of anatomical variations in the mandibular canal extending anteriorly. In this study $87 \%$ of the observations corroborate these findings.

\section{Assessment of the proximity between apexes and cortical plates}

The position of the root apexes and their relationship with cortical plates and respective thicknesses were initially the subject of studies using dried skulls and cadavers. ${ }^{4,14,20}$ Later, studies used sagittal $28,21,22,23$ and axial, ${ }^{7,19}$ tomographic sections, but with smaller samples and isolated groups of teeth. The present study assessed the proximity of the apexes of all the teeth in the dental arches to their adjacent cortical plates, except the third molars.

The assessment of the maxilla has shown that, except for the dental groups of molars, the majority of buccal apexes are at a distance of less than $1 \mathrm{~mm}$ from the outer cortical plate. This finding indicates that maxillary teeth should be given more attention in endodontic treatment planning, mainly canines and premolars, since more than $80 \%$ of these teeth are at a high-risk distance; this finding was corroborated by another study using similar methodology. ${ }^{40}$ However, about $40 \%$ of the palatal apexes of molars are at a high-risk distance in relation to the palatal cortical plate.

There were few apexes closely related to the buccal cortical plate in mandibular teeth. However, the group of second molars should be given special attention, since the majority of their apexes are at a distance less than $1 \mathrm{~mm}$ from the cortical plate. This is an interesting finding that does not seem to have been observed in the literature. When we performed the measurements, we could observe that the apical proximity of second molars to the lingual cortical plate is mainly the result of the contiguity of this site with the sub-mandibular fovea, which abruptly reduces the thickness of the bone at the region.

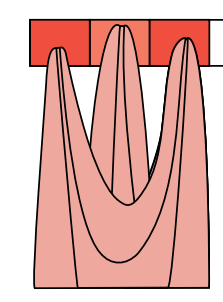

$2^{\text {nd }} M$

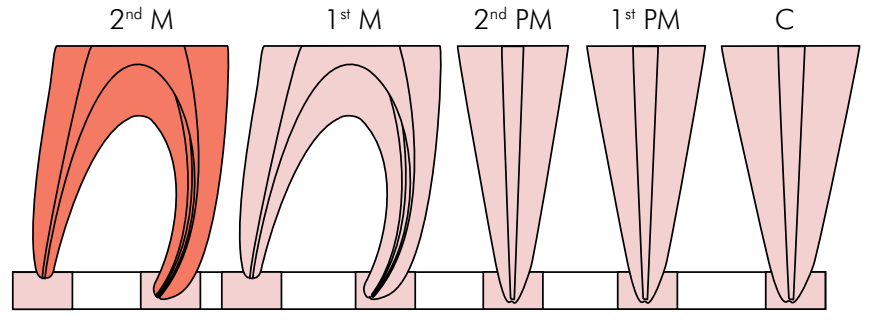

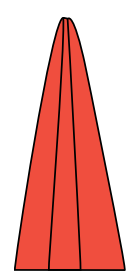
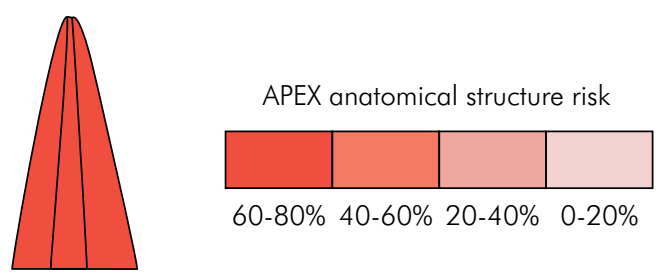

IL

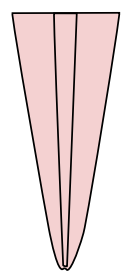

IC

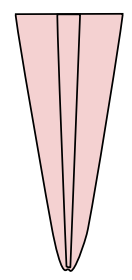

APEX cortical bone plate risk
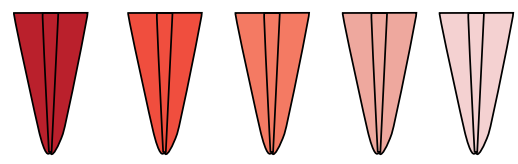

80-100\% $60-80 \% \quad 40-60 \% \quad 20-40 \% \quad 0-20 \%$

Figure 6. Odontogram of proximity risk as a guide for determining the working length. 
The authors were able to observe the percentage of occurrence of risky proximity, by grouping the data into risk classification tables. These tables can serve as a guide for performing instrumentation safely in endodontic treatment. We found that the higher the risk classification of a given apex in relation to anatomical or cortical structures, the higher the risk of complications.

It is recommended that practitioners use these data to provide them with a dynamic estimation to perform endodontic treatment planning. The present study presents an odontogram representing the percentage of risk for each root apex, This odontogram serves as a guide to determine the working length during treatment planning, when CBCT examination is not possible (Figure 6).

\section{Conclusion}

Most maxillary molars, mandibular molars and second premolars have a high-risk proximity to the near anatomical structures. Most maxillary and mandibular first premolars have a high-risk proximity to adjacent cortical plates. CBCT images are recommended for endodontic diagnosis and treatment when high-risk teeth are involved.

\section{References}

1. Oliveira MA, Quagliatto PS, Magalhães D, Biffi JC. Effects of bleaching agents and adhesive systems in dental pulp: a literature review. Braz J Oral Sci. 2012 Dec;11(4):428-32. https://doi.org/10.1590/S1677-32252012000400001

2. Kwon SJ, Park YJ, Jun SH, Ahn JS, Lee IB, Cho BH, et al. Thermal irritation of teeth during dental treatment procedures. Restor Dent Endod. 2013 Aug;38(3):105-12. https://doi.org/10.5395/rde.2013.38.3.105

3. Fouad AF. Microbiological aspects of traumatic injuries. Dent Traumatol. 2019 Dec;35(6):324-32. https://doi.org/10.1111/edt.12494

4. Eberhardt JA, Torabinejad M, Christiansen EL. A computed tomographic study of the distances between the maxillary sinus floor and the apices of the maxillary posterior teeth. Oral Surg Oral Med Oral Pathol. 1992 Mar;73(3):345-6. https://doi.org/10.1016/0030-4220(92)90133-B

5. Hiremath H, Agarwal R, Hiremath V, Phulambrikar T. Evaluation of proximity of mandibular molars and second premolar to inferior alveolar nerve canal among central Indians: A cone-beam computed tomographic retrospective study. Indian J Dent Res. 2016 May-Jun;27(3):312-6. https://doi.org/10.4103/0970-9290.186240

6. Lavasani SA, Tyler C, Roach SH, McClanahan SB, Ahmad M, Bowles WR. Cone-beam computed tomography: anatomic analysis of maxillary posterior teeth-impact on endodontic microsurgery. J Endod. 2016 Jun;42(6):890-5. https://doi.org/10.1016/j.joen.2016.03.002

7. Kang SH, Kim BS, Kim Y. Proximity OF POSTERIOR TEETH TO THE MAXILLARY SINUS AND BUCCAL BONE THICKNESS: A BIOMETRIC ASSESSMENT USING CONE-BEAM COMPUTED TOMOGRAPHY. J Endod. 2015 Nov;41(11):1839-46. https://doi.org/10.1016/i.joen.2015.08.011

8. Bürklein S, Grund C, Schäfer E. Relationship between root apices and the mandibular canal: a cone-beam computed tomographic analysis in a German Population. J Endod. 2015 Oct;41(10):1696-700. https://doi.org/10.1016/i.joen.2015.06.016

9. Chong BS, Quinn A, Pawar RR, Makdissi J, Sidhu SK. The anatomical relationship between the roots of mandibular second molars and the inferior alveolar nerve. Int Endod J. 2015 Jun;48(6):549-55. https://doi.org/10.1111/iej.12348

10. Denio D, Torabinejad M, Bakland LK. Anatomical relationship of the mandibular canal to its surrounding structures in mature mandibles. J Endod. 1992 Apr;18(4):161-5. https://doi.org/10.1016/S0099-2399(06)81411-1

11. Estrela C, Nunes CA, Guedes OA, Alencar AH, Estrela CR, Silva RG, et al. Study of anatomical relationship between posterior teeth and maxillary sinus floor in a subpopulation of the brazilian central region using cone-beam computed tomography - Part 2. Braz Dent J. 2016 Jan-Feb;27(1):9-15. https://doi.org/10.1590/0103-6440201600679

12. Kilic C, Kamburoglu K, Yuksel SP, Ozen T. An Assessment of the relationship between the maxillary sinus floor and the maxillary posterior teeth root tips using dental cone-beam computerized tomography. Eur J Dent. 2010 Oct;4(4):462-7. https://doi.org/10.1055/s-0039-1697866

13. Kovisto T, Ahmad M, Bowles WR. Proximity of the mandibular canal to the tooth apex. J Endod. 2011 Mar;37(3):311-5. https://doi.org/10.1016/j.joen.2010.11.030

14. Kwak HH, Park HD, Yoon HR, Kang MK, Koh KS, Kim HJ. Topographic anatomy of the inferior wall of the maxillary sinus in Koreans. Int J Oral Maxillofac Surg. 2004 Jun;33(4):382-8. https://doi.org/10.1016/j.ijom.2003.10.012

15. Roque-Torres GD, Ramirez-Sotelo LR, Almeida SM, Ambrosano GM, Bóscolo FN. 2D and 3D imaging of the relationship between maxillary sinus and posterior teeth. Braz J Oral Sci. 2015 Jun;14(2):141-8. https://doi.org/10.1590/1677-3225v14n2a09 
16. Simonton JD, Azevedo B, Schindler WG, Hargreaves KM. Age- and gender-related differences in the position of the inferior alveolar nerve by using cone beam computed tomography. J Endod. 2009 Jul;35(7):944-9. https://doi.org/10.1016/i.joen.2009.04.032

17. Arx T, Fodich I, Bornstein MM. Proximity of premolar roots to maxillary sinus: a radiographic survey using cone-beam computed tomography. J Endod. 2014 Oct;40(10):1541-8. https://doi.org/10.1016/i.joen.2014.06.022

18. Fuentes R, Flores T, Navarro P, Salamanca C, Beltrán V, Borie E. Assessment of buccal bone thickness of aesthetic maxillary region: a cone-beam computed tomography study. J Periodontal Implant Sci. 2015 Oct;45(5):162-8. https://doi.org/10.5051/ipis.2015.45.5.162

19. Jin GC, Kim KD, Roh BD, Lee CY, Lee SJ. Buccal bone plate thickness of the Asian people. J Endod. 2005 Jun;31(6):430-4. https://doi.org/10.1097/01.don.0000145430.35906.fa

20. Han JY, Jung GU. Labial and lingual/palatal bone thickness of maxillary and mandibular anteriors in human cadavers in Koreans. J Periodontal Implant Sci. 2011 Apr;41(2):60-6. https://doi.org/10.5051/ipis.2011.41.2.60

21. Nahás-Scocate AC, Brandão AS, Patel MP, Lipiec-Ximenez ME, Chilvarquer I, Valle-Corotti KM. Bone tissue amount related to upper incisors inclination. Angle Orthod. 2014 Mar;84(2):279-85. https://doi.org/10.2319/031213-211.1

22. Nowzari H, Molayem S, Chiu CH, Rich SK. Cone beam computed tomographic measurement of maxillary central incisors to determine prevalence of facial alveolar bone width $\geq 2$ mm. Clin Implant Dent Relat Res. 2012 Aug;14(4):595-602. https://doi.org/10.1111/j.1708-8208.2010.00287.x

23. Vera C, De Kok IJ, Reinhold D, Limpiphipatanakorn P, Yap AK, Tyndall D, et al. Evaluation of buccal alveolar bone dimension of maxillary anterior and premolar teeth: a cone beam computed tomography investigation. Int J Oral Maxillofac Implants. 2012 Nov-Dec;27(6):1514-9.

24. Behrents KT, Speer ML, Noujeim M. Sodium hypochlorite accident with evaluation by cone beam computed tomography. Int Endod J. 2012 May;45(5):492-8. https://doi.org/10.1111/j.1365-2591.2011.02009.x

25. Alfouzan K, Jamleh A. Fracture of nickel titanium rotary instrument during root canal treatment and re-treatment: a 5-year retrospective study. Int Endod J. 2018 Feb;51(2):157-63. https://doi.org/10.1111/iej.12826

26. Bürklein S, Benten S, Schäfer E. Quantitative evaluation of apically extruded debris with different single-file systems: Reciproc, F360 and OneShape versus Mtwo. Int Endod J. 2014 May;47(5):405-9. https://doi.org/10.1111/iej.12161

27. Coskunses FM, Sinanoglu A, Helvacioglu-Yigit D, Abbott PV. The extrusion of root canal cement containing paraformaldehyde into the inferior alveolar nerve canal resulting in infection and numbness. Int Endod J. 2016 Jun;49(6):610-7. https://doi.org/10.1111/iej.12510

28. Tilotta-Yasukawa F, Millot S, El Haddioui A, Bravetti P, Gaudy JF. Labiomandibular paresthesia caused by endodontic treatment: an anatomic and clinical study. Oral Surg Oral Med Oral Pathol Oral Radiol Endod. 2006 Oct;102(4):e47-59. https://doi.org/10.1016/j.tripleo.2006.02.017

29. Yadav SS, Shah N, Naseem A, Roy TS, Sood S. Effect of "apical clearing" and "apical foramen widening" on apical ramifications and bacterial load in root canals. Bull Tokyo Dent Coll. 2014;55(2):67-75. https://doi.org/10.2209/tdcpublication.55.67

30. Borlina SC, de Souza V, Holland R, Murata SS, Gomes-Filho JE, Dezan Junior E, et al. Influence of apical foramen widening and sealer on the healing of chronic periapical lesions induced in dogs' teeth. Oral Surg Oral Med Oral Pathol Oral Radiol Endod. 2010 Jun;109(6):932-40. https://doi.org/10.1016/j.tripleo.2010.01.028

31. Wu MK, Wesselink PR, Walton RE. Apical terminus location of root canal treatment procedures. Oral Surg Oral Med Oral Pathol Oral Radiol Endod. 2000 Jan;89(1):99-103. https://doi.org/10.1016/S1079-2104(00)80023-2

32. Berman LH, Fleischman SB. Evaluation of the accuracy of the Neosono-D electronic apex locator. J Endod. 1984 Apr;10(4):164-7. https://doi.org/10.1016/S0099-2399(84)80121-1

33. Piasecki L, Carneiro E, Silva Neto UX, Westphalen VP, Brandão CG, Gambarini G, et al. The use of micro-computed tomography to determine the accuracy of 2 electronic apex locators and anatomic variations affecting their precision. J Endod. 2016 Aug;42(8):1263-7. https://doi.org/10.1016/i.joen.2016.04.024

34. El Hachem R, Wassef E, Mokbel N, Abboud R, Zogheib C, El Osta N, et al. Influence of the maxillary sinus on the accuracy of the root ZX apex locator: an ex vivo study. Dent J (Basel). 2019 Jan;7(1):E3. https://doi.org/10.3390/dj7010003

35. Ee J, Fayad MI, Johnson BR. Comparison of endodontic diagnosis and treatment planning decisions using cone-beam volumetric tomography versus periapical radiography. J Endod. 2014 Jul;40(7):910-6. https://doi.org/10.1016/i.joen.2014.03.002

36. Venskutonis T, Plotino G, Juodzbalys G, Mickevičienè L. The importance of cone-beam computed tomography in the management of endodontic problems: a review of the literature. J Endod. 2014 Dec;40(12):1895-901. https://doi.org/10.1016/i.joen.2014.05.009

37. Mota de Almeida FJ, Knutsson K, Flygare L. The impact of cone beam computed tomography on the choice of endodontic diagnosis. Int Endod J. 2015 Jun;48(6):564-72. https://doi.org/10.1111/iej.12350

38. Patel S, Durack C, Abella F, Shemesh H, Roig M, Lemberg K. Cone beam computed tomography in Endodontics - a review. Int Endod J. 2015 Jan;48(1):3-15. https://doi.org/10.1111/iej.12270

39. Rottke D, Dreger J, Sawada K, Honda K, Schulze D. Comparison of manual and dose reduction modes of a MORITA R100 CBCT. Dentomaxillofac Radiol. 2019 Feb;48(2):20180009. https://doi.org/10.1259/dmfr.20180009

40. Ariji Y, Obayashi N, Goto M, Izumi M, Naitoh M, Kurita K, et al. Roots of the maxillary first and second molars in horizontal relation to alveolar cortical plates and maxillary sinus: computed tomography assessment for infection spread. Clin Oral Investig. 2006 Mar;10(1):35-41. https://doi.org/10.1007/s00784-005-0020-5 